\title{
Three species of Colletotrichum are associated with anthracnose of pomegranate in Brazil
}

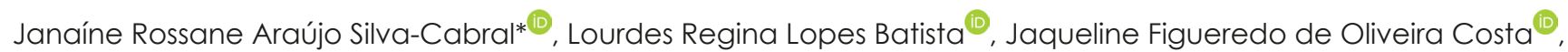 \\ Edna Peixoto da Rocha Amorim ${ }^{\circledR}$, Gaus Silvestre de Andrade Lima ${ }^{\circledR}$, Iraildes Pereira Assunção ${ }^{\circledR}$
}

Federal University of Alagoas, Rio Largo, Brazil

*Corresponding author, e-mail: janaine_rossane@hotmail.com

\begin{abstract}
Pomegranate is a fruit rich in vitamins and secondary metabolites used in traditional medicine and industry. However, production losses have been associated the anthracnose, disease caused by Colletotrichum species. This is an important disease of the pomegranate, as it affects the yield and the quality of the fruits. The present study aimed to investigate which species of Colletotrichum are associated with anthracnose disease in pomegranate in the Northeast region of Brazil, using multi-locus phylogenetic analysis and morpho-cultural characteristics. The total DNA extracted was amplified with GAPDH, TUB2, CAL, ACT genes and the ITS-rDNA region. The sequences obtained were used for the construction of phylogenetic trees of Bayesian inference. The mycelial growth rate, size and shape of the conidia and appressories were evaluated for the morpho-cultural characterization of the species. Six isolates were analysis and three species belonging to the C. gloeosporioides complex were identified in this study. This is the first report of $C$. theobromicola (2) in pomegranate fruit in Brazil and C. siamense (2) and C. fructicola (2) in the world.
\end{abstract}

Keywords: Colletotrichum fructicola, Colletotrichum siamense, Colletotrichum theobromicola, Punica granatum, multilocus phylogeny

Pomegranate (Punica granatum L.) is a tree native to the Middle East but it is well adapted to the climatic conditions of Brazil. Commercial production of pomegranate has expanded internationally as well as within Brazil due to increasing interest from farmers. The fruit is rich in nutrients and active principles that can be used in the cosmetic, pharmaceutical and food industry (Kanetis et al., 2015; Hmid et al., 2017).

However, fungi of the genus Colletotrichum Corda have harmed the yield of this culture, causing the anthracnose disease. Anthracnose fruit rot is considered one of the most important fungal diseases of the pomegranate, both in pre-harvest and post-harvest, because it leads to significant financial losses, mainly due to the rot symptoms that depreciate the fruit and lead to rapid deterioration (Munhuweyi et al., 2016).

Although different species of the genus Colletotrichum cause anthracnose in several hosts, only the species Colletotrichum gloeosporiodes (Penz.) Penz. \& Sacc had been reported in pomegranate, because its identification was based exclusively on morphological studies, host range and analysis of the internal ribosomal transcribed spacer region (ITS-rDNA) (Lakshmi et al., 2011; Thomidis \& Exadaktylou, 2011; Rahimlou et al., 2014).

Nevertheless, the current taxonomy of the Colletotrichum genus has been based on multi-locus phylogenetic studies combined with phenotypic characteristics. Studies using these approaches concluded that C. gloeosporiodes is a complex of species (Weir et al., 2012; Jayawardena et al., 2016). In addition, the species C. theobromicola Delacr. Bull and C. tropicale E.I. Rojas, S.A. Rehner \& Samuels were reported on pomegranate fruits in India and Brazil, respectively, and C. nymphaeae (Pass.) Aa, C. fioriniae (Marcelino \& Gouli) R.G. Shivas \& Y.P. Tan, C. simmondsii R.G. Shivas \& Y.P. Tan, C. theobromicola, C. siamense Prihastuti L. Cai 
\& K.D. Hyde, and C. gloeosporioides on pomegranate in United States, all using multi-locus analysis (Sharma et al., 2015; Silva-Cabral et al., 2019; Xavier et al., 2019). Therefore, the present study aimed to investigate which Colletotrichum species are associated with anthracnose disease on pomegranate in the northeastern region in Brazil, based in multi-locus phylogeny and morphocultural characteristics' approaches.

Pomegranate fruits with circulars necrotic lesions were collected from domestic growers and food fairs from August 2012 until March 2013, in the states of Alagoas, Pernambuco and Bahia in Brazil. The isolates were obtained from symptomatic pomegranates and grown on potato-dextrose-agar (PDA). The colonies were stored in the Culture Collection of Phytopathogenic Fungi at the Universidade Federal de Alagoas (COUFAL).

Healthy pomegranate fruits (one fruit by isolate) were submitted to pathogenicity. Each fruits wounded by a needle sterile were inoculated with two $5 \mathrm{~mm}$ mycelial plugs (seven days old) placed separated equidistant from each other and kept in humid chamber. Control fruits were inoculated with agar plugs.

The total DNA was obtained from single-spore colonies growing for 7 days using the extraction protocol described by Doyle \& Doyle (1987) and submitted to PCR reactions for amplification of the ITS-rDNA region, and partial sequences of the $\beta$-tubulin (TUB2) genes, glyceraldehyde-3-phosphate (GAPDH), calmodulin $(C A L)$ and actin $(A C T)$. The PCR conditions were the same as described by Weir et al. (2012). The products of the PCR reaction were purified and sequenced in both directions with the same primers used for amplification.

Sequences of the amplified regions were assembled using the Staden Package software and compared against the GenBank database for preliminary identification of the species. Next, the alignment of the consensus sequences was manually adjusted using the MUSCLE algorithm in MEGA6. The Bayesian Inference analysis (BI) was performed employing the method of the Markov chain Monte Carlo (MCMC) at the CIPRES web portal using MrBayes v. 3.2.3 to construct phylogenetic trees. The best nucleotide substitution model was determined for data from each genomic region using MrModeltest according to the Akaike Information Criterion (AIC). An initial BI analysis using the GAPDH data set was performed for the seven isolates obtained in this study. A second Bl analysis was carried out to confirm the identification of the isolates based on the concatenated data set (ACT, CAL, GAPDH, ITS and TUB2).

Sequences of the species from C. gloeosporiodes complex obtained from GenBank were included in the analysis (Table supplementary 1). The partial sequences obtained in this study were deposited in GenBank. The alignment and tree were deposited in TreeBASE (http:// www.treebase.org; accession number: 23044).

For morpho-cultural characterization, colonies were grown on synthetic PDA incubated at $25^{\circ} \mathrm{C}$ for 7 days and measured daily. The colour of the colonies was evaluated in the 7th day. Format and size of fifty conidia and appressories were also measured. Data were submitted to analysis of variance (ANOVA) $(p<0.05)$ by Tukey's test.

Six isolates were obtained from Alagoas (COUFAL0042, COUFAL0043, COUFAL0044), Bahia (COUFAL0040 and COUFAL0041) and Pernambuco (COUFAL0049). All isolates tested caused symptoms at 7 to 10 days after inoculation. The control fruits showed no symptoms. Sequences of the GAPDH gene showed high similarity with sequences of three species from $C$. gloeosporioides complex deposited in the GenBank: C. siamense, C. theobromicola and C. fructicola Prihastuti L. Cai \& K.D. Hyde. The results of both phylogenetic BI analysis confirmed the prior identification of these three species (Figure 1).

The isolates produced hyaline, straight, cylindrical to clavate conidia with often broadly rounded ends and brown appressoria of irregular format. Colonies varied between grey to white with mean growth of $5.8 \mathrm{~mm}$ /day (Table1). All morpho-cultural features were similar to the species from C. gloeosporioides complex (Rojas et al., 2010; Weir et al., 2012).

These species are widespread in different world locations causing anthracnose on several hosts. However, C. fructicola was not previously reported on pomegranate anywhere in the world, while C. siamense and $\mathrm{C}$. theobromicola were reported only in the USA and the latter also in India, probably because of the lack of studies using multi-locus phylogeny for the identification of species from Colletotrichum in this host (Alaniz et al., 2015; Meetum et al., 2015; Sharma et al., 2015; Liu et al., 2016; Costa et al., 2019). Moreover, the species C. gloeosporioides was not reported in the present study.

Studies carried out in Brazil with other hosts using multi-locus phylogenetic, in which anthracnose had also been attributed exclusively $C$. gloeosporioides based in morphological characteristics, corroborate with this result, reporting $C$. fructicola on cashew, pine cone, soursop and mango; C.siamense on cashew, pine cone, soursop and mango, $C$. tropicale on cashew, pomegranate, pine cone, soursop and mango, C. asianum on mango, $C$. 


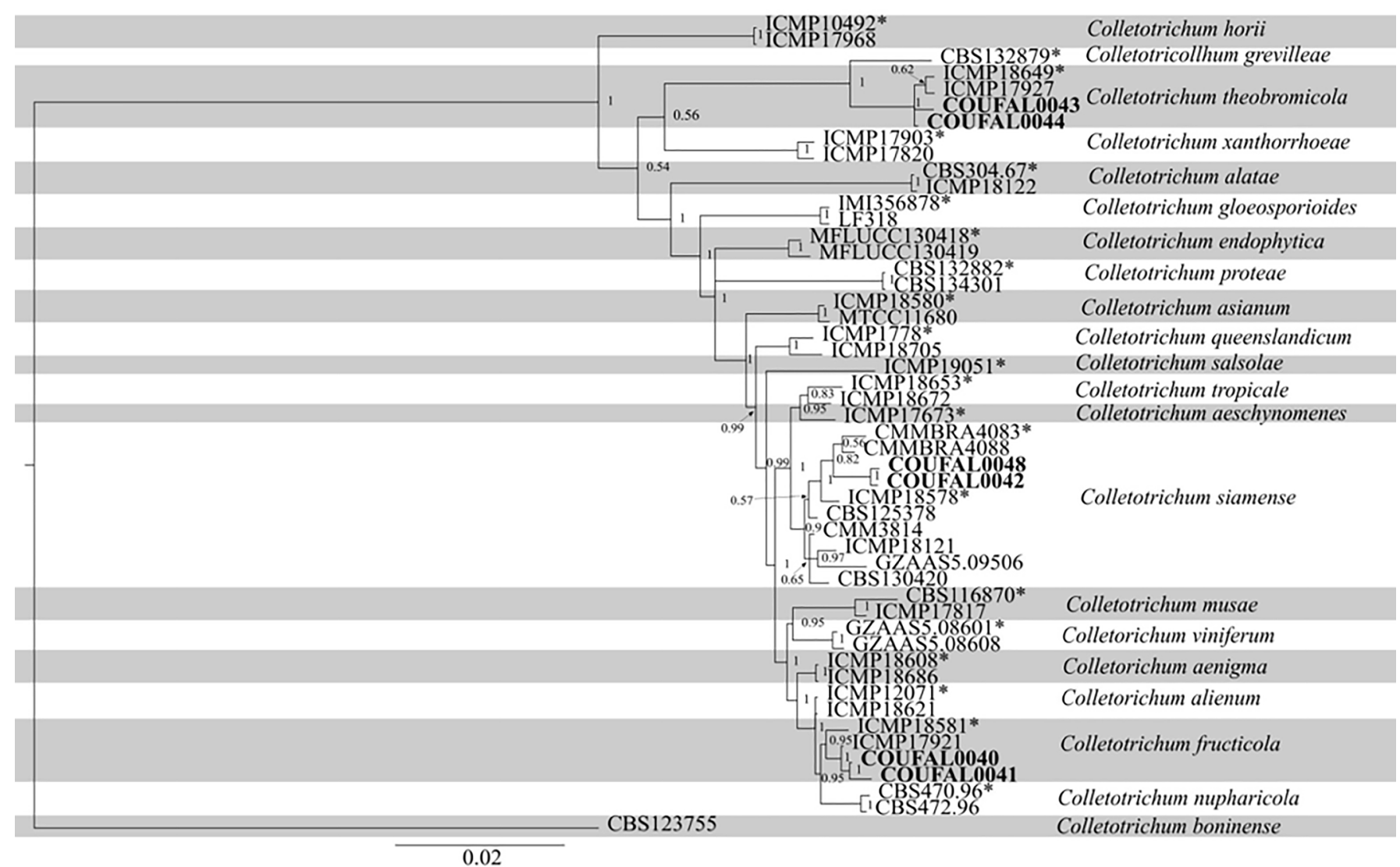

Figure 1. Multi-locus phylogenetic tree inferred from the Bayesian analysis using GAPDH, TUB2, ACT and CAL genes and ITS region for C. gloeosporioides complex. The combined data set consisted of 2614 nucleotides. The SYM+I model of evolution was used for all gene. The values of posterior probability $>0.5$ are indicated above knots. Ex-type cultures are marked with an asterisk. The strains used in this study are emphasized in bold. The tree was rooted with Colletotrichum boninense.

Table 1.Summary of morphological and cultural characteristic of Colletotrichum strains.

\begin{tabular}{|c|c|c|c|c|c|c|c|}
\hline \multirow[t]{2}{*}{ Species } & \multicolumn{3}{|c|}{ Conidia ( $\mu \mathrm{m})$} & \multicolumn{2}{|c|}{ Appressoria ( $\mu \mathrm{m})$} & \multirow{2}{*}{$\begin{array}{c}\text { Growth rate } \\
\text { (mm/day) }\end{array}$} & \multirow[t]{2}{*}{ Colonies } \\
\hline & Length & Width & Shape & Length & Width & & \\
\hline $\begin{array}{l}\text { C. fructicola } \\
\text { COUFAL0040 } \\
\text { COUFAL0041 }\end{array}$ & $\begin{array}{c}13.2 \mathrm{c} \\
(7.72-18.12)\end{array}$ & $\begin{array}{c}4.3 \mathrm{~b} \\
(2.31-6.04)\end{array}$ & Cylindrical & $\begin{array}{c}9.7 a \\
(7.07-14.17)\end{array}$ & $\begin{array}{c}6.5 b \\
(4.43-9.19)\end{array}$ & $4.0 c$ & $\begin{array}{l}\text { Greyish, } \\
\text { greendarkreverse }\end{array}$ \\
\hline $\begin{array}{l}\text { C. theobromicola } \\
\text { COUFAL0043 } \\
\text { COUFAL0044 }\end{array}$ & $\begin{array}{c}16.7 a \\
(13.32-20.95)\end{array}$ & $\begin{array}{c}4.6 a \\
(3.18-5.68)\end{array}$ & Cylindricaltoclavate & $\begin{array}{c}8.5 b \\
(6.6-11.79)\end{array}$ & $\begin{array}{c}6.6 \mathrm{~b} \\
(4.13-9.28)\end{array}$ & $6.2 \mathrm{a}$ & $\begin{array}{c}\text { Gray with white } \\
\text { edges, dark gray } \\
\text { reverse }\end{array}$ \\
\hline $\begin{array}{l}\text { C. siamense } \\
\text { COUFAL0042 } \\
\text { COUFAL0048 }\end{array}$ & $\begin{array}{c}14.2 \mathrm{~b} \\
(12.59-17.62)\end{array}$ & $\begin{array}{c}4.6 a \\
(3.68-5.37)\end{array}$ & Cylindrical & $\begin{array}{c}9.7 a \\
(5.8-15.19)\end{array}$ & $\begin{array}{c}7.3 a \\
(5.1-10.43)\end{array}$ & $5.3 b$ & $\begin{array}{l}\text { White, } \\
\text { greenishreverse }\end{array}$ \\
\hline
\end{tabular}

theobromicola on pine cone and soursop, C. chrysophilum, C. fragariae and C. queenslandicum on cashew (Lima et al., 2013; Veloso et al., 2018; Costa et al., 2019; SilvaCabral et al., 2019). Colletotrichum gloeosporioides was reported only in the studies of Costa et al. (2019) and Veloso et al. (2018), but with low incidence, one isolate obtained from pine cone leaf and two isolates obtained from cashew inflorescence, respectively.

These results raise an intriguing question about this species that needs to be better clarified: Does this species behave as an endophytic pathogen, as indicated by the study of Waculicz-Andrade et al. (2017) or is it not a common tropic pathogen as concluded by Phoulivong et al. (2010)?
This is the first report of the species C. fructicola causing anthracnose on pomegranate fruits in the world and of C. siamense and C. theobromicola in Brazil. This knowledge is critical to the development of more efficient control measures of anthracnose disease of pomegranate, inasmuch as, little was known about the Colletotrichum species associated with this crop.

\section{Acknowledgments}

This study was financed in part by the Coordenação de Aperfeiçoamento de Pessoal de Nível Superior - Brasil (CAPES) - Finance Code 001. This work also was supported by Fundação de Amparo à Pesquisa do Estado de Alagoas -FAPEAL. 


\section{References}

Alaniz, S., Hernández L., Mondino P. 2015. Colletotrichum fructicola is the dominant and one of the most aggressive species causing bitter rot of apple in Uruguay. Tropical Plant Pathology 40: 265-274.

Costa, J.F.O., Kamei, S.H., Silva, J.R.A., Miranda, A.R.G.S., Netto, M.B., Silva, S.J.C., Correia, K.C., Lima, G.S.A., Assunção, I.P. 2019. Species diversity of Colletotrichum infecting Annona spp. in Brazil. European Journal of Plant Pathology 53: 169-180.

Doyle, J.J., Doyle, J.L. 1987. A rapid DNA isolation procedure for small quantities of fresh leaf tissue. Phytochemical Bulletin 19: 11-15.

Hmid, I., Elothmani, D., Hanine, H., Oukabli, A., Mehinagic, E. 2017. Comparative study of phenolic compounds and their antioxidant attributes of eighteen pomegranate (Punica granatum L.) cultivars grown in Morocco. Arabian Journal of Chemistry 10: 2675-2684.

Jayawardena, R.S., Hyde, K.D., Damm, U., Cai, L., Liu, M., Li, X.H., Zhang, W., Zhao, W.S., Yan, J.Y. 2016. Notes on currently accepted species of Colletotrichum. Mycosphere 7: 1192-1260.

Kanetis, L., Testempasis, S., Goulas, V., Samuel, S., Myresiotis, C., Karaoglanidis, G.S. 2015. Identification and mycotoxigenic capacity of fungi associated with preand postharvest fruit rots of pomegranates in Greece and Cyprus. International Journal of Food Microbiology 208: 84-92.

Lakshmi, B.K.M., Reddy, P.N., Prasad, R.D. 2011. Crossinfection potential of Colletotrichum gloeosporioides Penz. isolates causing anthracnose in subtropical fruit crops. Tropical Agricultural Research 22: 183-193.

Lima, N.B., Batista, M.V.A., De Morais Jr, M.A., Barbosa, M.A.G., Michereff, S.J., Hyde, K.D., Câmara, M.P.S. 2013. Five Colletotrichum species are responsible for mango anthracnose in northeastern Brazil. Fungal Diversity 61: 75-88.

Liu, F., Tang, G., Zheng, X., LI, Y., Sun, X., Qi, X., Zhou, Y., Xu, J., Chen, H., Chang, X., Zhang, S., Gong, G. 2016. Molecular and phenotypic characterization of Colletotrichum species associated with anthracnose disease in peppers from Sichuan Province, China. Scientific Reports 6: 32761.

Meetum, P., Leksomboon, C., Kanjanamaneesath, M. 2015. First report of Colletotrichum aenigma and $C$. siamense, the causal agent of anthracnose disease of dragon fruit in thailand. Journal of Plant Pathology 97: 391-403.

Munhuweyi, K., Lennox, C.L., Meitz-Hopkins, J.C., Caleb, O.J., Opara, U.L. 2016. Major diseases of pomegranate (Punica granatum L.), their causes and management - A review. Scientia Horticulturae 211:126-139.

Phoulivong, S., Cai, L., Chen, H., Mckenzie, E.H.C., Abd-Elsalam, K., Chukeatirote, E., Hyde, K.D. 2010. Colletotrichum gloeosporioides is not a common pathogen on tropical fruits. Fungal Diversity 44: 33-43.
Rahimlou, S., Babaeizad, V., Sayari, M. 2014.First report of fruit spot on pomegranate caused by Colletotrichum gloeosporioides in Iran. Journal of Plant Pathology 96: 603-611.

Rojas, E.I., Rehner, S.A., Samuels, G.J., Van Bael, S.A., Herre, E.A., Cannon, P., Chen, R., Pang, J., Wang, R., Zhang, Y., Peng, Y.Q., Sha, T. 2010. Colletotrichum gloeosporioides s.l. associated with Theobroma cacao and other plants in Panamá: Multilocus phylogenies distinguish hostassociated pathogens from asymptomatic endophytes. Mycologia 102: 1318-1338.

Sharma, G., Pinnaka, A.K., Shenoy, B.D. 2015. Resolving the Colletotrichum siamense species complex using ApMat marker. Fungal Diversity 71: 247-264.

Silva-Cabral, J.R.A., Batista, L.R.L., Costa, J.F.O., Ferro, M.M., Silva, S.J.C., Lima, G.S.A., Assunção, I.P. 2019. First report of Colletotrichum tropicale causing anthracnose on pomegranate in Brazil. Plant Disease 103: 583.

Thomidis, T., Exadaktylou, E. 2011. Occurrence of a fruit spot disease of pomegranates caused by Colletotrichum gloeosporiodes in the prefecture of Komotini, Greece. Plant Disease 95: 872.

Veloso, J.S., Câmara, M.P.S., Lima, W.G., Michereff, S.J., Doyle, V.P. 2018. Why species delimitation matters for fungal ecology: Colletotrichum diversity on wild and cultivated cashew in Brazil. Fungal Biology 122: 677-691.

Waculicz-Andrade, C.E., Savi, D.C., Bini, A.P., Adamoski, D., Goulin, E.H., Silva Jr, G.J., Massola Jr, N.S., Terasawa, L.G., Kava, V., Glienke, C. 2017. Colletotrichum gloeosporioides sensu stricto: an endophytic species or citrus pathogen in Brazil? Australasian Plant Pathology 46:191-203.

Weir, B.S., Johnston, P.R., Damm, U. 2012. The Colletotrichum gloeosporioides species complex. Studies in Mycology 73: 115-180.

Xavier, K.V., Kc, A.N., Peres, N.A., Deng, Z., Castle, W., Lovett, W., Vallad, G.E. 2019. Characterization of Colletotrichum species causing anthracnose of pomegranate in the Southeastern United States. Plant Disease 103: 2771-2780.

Conflict of Interest Statement: The authors declare that the research was conducted in the absence of any commercial or financial relationships that could be construed as a potential conflict of interest.

All the contents of this journal, except where otherwise noted, is licensed under a Creative Commons Attribution License attribuition-type BY. 